\title{
Isthmocele: A Review of Management Options for This Novel Entity Amanjot Kaurl, Ayesha Ahmad ${ }^{2}$
}

\begin{abstract}
:
The incidence of cesarean section is on rise all over the world and so are the complications associated with the procedure. Isthmocele as a complication of cesarean section is becoming a well documented entity all over the world in medical literature. It presents with symptoms like prolonged post menstrual bleeding, chronic pelvic infection and infertility. A pregnancy can get lodged in this area and can have disastrous consequences for the patient. The present article is an attempt to review to various presenting complaints, diagnosis and management of Isthmocele.
\end{abstract}

Keywords: Isthmocele, uteroperitoneal fistula, niche, cesarean scar defect, uterine diverticulum

International Journal of Human and Health Sciences Vol. 03 No. 03 July'19 Page : 127-133 DOI: http://dx.doi.org/10.31344/ijhhs.v3i3.90

\section{Introduction:}

Isthmocele is a pouchlike defect of the anterior uterine isthmus at the site of a prior cesarean

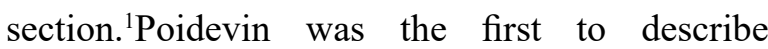
this term in 1961. Later on, Morris in 1995 confirmed the presence of this entity while analysing uterine specimens of hysteroctomised patients. ${ }^{2}$ Alternatively known as a niche, cesarean scar defect,uteroperitoneal fistula or uterine diverticulum, isthmocele has gained increasing importance in the past decade.

The worldwide prevalence has been estimated to vary from $19 \%$ to as high as $84 \%$ in some studies ${ }^{3-7}$ It is widely accepted that the prevalence figures may be biased and not give a true estimate of the problem due to lack of clinical awareness, variation in symptomatology and absence of standardized diagnostic clinical and radiological criteria.

Due to the rising incidence of Isthmocele and increasing awareness of the wide range of gynaecological symptoms associated with it, we conducted this review to understand the disease pathology and its implications.

\section{Data Identification}

Medline, Pubmed, Google Scholar and Scorpus electronic databases were searched for systematic reviews and case reports and case series. The databases were searched using relevant $\mathrm{MeSH}$ terms, including all subheadings, and this was combined with a keyword search. Search words included 'niche', 'cesarean scar defect', 'Isthmocele', 'Isthmocele diagnosis and management' and ' uteroperitoneal fistula'.

\section{Etiopathogenesis and Risk factors:}

Ever since its first description, there have been different theories on etiology of isthmocele. The most widely accepted one attributes development of isthmocele to the inadequate healing of myometrium at cesarean scar site.

\section{Effect of technique of hysterotomy closure:}

One of the reasons stated for inappropriate healing was the technique of suturing hysterotomy incision. A double layer closure of uterine cavity has been found to be associated with decreased incidence of niche formation. However, this

1. Dr Amanjot KaurM.D. [Obst. And Gynae] Fellow in Advanced Gynaecology Laparoscopy, Sunrise Hospital, Delhi, India. aman50055@yahoo.com

2. Dr Ayesha Ahmad, D.G.O., D.N.B. [Obst. And Gynae], M.N.M.A.S., M.R.C.O.G. [U.K.] Fellow in Advanced Gynaecology Laparoscopy, Sunrise Hospital, Delhi, India. E-mail: docayeshaahmad@gmail.com

Correspondence to: Dr Ayesha Ahmad, D.G.O., D.N.B. [Obst. And Gynae], M.N.A.M.S., M.R.C.O.G. [U.K.] Fellow in Advanced Gynaecology Laparoscopy, Sunrise Hospital, Delhi, India.Email docayeshaahmad@gmail.com 
remains a debatable topic and a recent metaanalysis found no significant difference for niche formation with either single layer or double layer hysterotomy closure. ${ }^{8}$

Endometrium sparing repairs not approaching the myometrium in its entire width,locking sutures, lack of peritonization causing adhesion formation and pull on the scar, and interrupted suturing techniques are other factors associated with the development of isthmocele. ${ }^{9}$ The use of a delayed absorbable suture in combination with ischemic technique of suturing may result in abnormal healing. ${ }^{10}$

\section{Effect of site of incision:}

Myometrial healing might be compromised with a uterine incision which is given so low that cervical glands become entrapped in the stitch line. Therefore, second stage cesarean sections are at a higher risk of inadequate healing. An incision given too high with respect to lower uterine segment may result in myometrial reconstruction and a resultant weak functional myometrium predisposing it to niche formation. ${ }^{11,12}$

\section{Effect of anatomy of uterus:}

In patients with retroflexed uterus, the cesarean scar remains at higher traction causing Isthmocele.

\section{Effect of number of cesarean sections:}

Repeated cesarean sections are purported to be associated with decreased perfusion of scar tissue, altered scar healing and progressive thinning of the area leading to isthmocele formation.

Literature quotes the incidence of Isthmocele as $62 \%$ after one, $68.2 \%$ two and $77.8 \%$ after three cesarean sections respectively. ${ }^{6}$

\section{Other factors:}

Interestingly, the use of adhesion barriers and applied sutures promote the formation of isthmocele. ${ }^{11}$ Some researchers have also described preeclampsia, gestational diabetes and diabetes mellitus as high risk factors.

\section{Clinical features}

Women may asymptomatic or present with menstrual irregularities, dysmenorrhea, pelvic pain and infertility. The symptomatology and sequelae of Isthmocele have been described in the literature as " cesarean scar syndrome". Post menstrual bleeding is the most commonly reported symptom in isthmocele. It is postulated that during menstruation, blood and debris collects in the isthmocelediverticulum which later on leads to bleeding which may last from 2 to 12 days. We don't know exactly why blood tends to collect in this pseudocavity; decreased contractility of myometrium may be a contributory reason or it may be that the fibrotic edge of the pouch might act as a hindrance to drainage of blood.

Investigators have reported the prevalence of abnormal uterine bleeding to be as high as $28.9 \%$ to $30 \%$ [Vervoot et al, van der Voet et al] in women with uteroperitoneal fistula as compared to $6.9 \%$ in women without any evidence of fistula. ${ }^{13,14}$ The amount and duration of bleeding correlates with the size of the diverticular sac. Women with a sac diameter more than adjacent myometrium report a higher incidence of bleeding. ${ }^{15,16}$

Diagnostic hysteroscopy in such women reveals the presence of fragile vessels in the sac which lends credence to the theory that the source of bleeding is the isthmocele sac itself. Histopathological examination shows presence of red blood cells in the endometrial stroma of the sac. ${ }^{3}$

The second most commonly reported symptom is dysmenorrhea. Various studies have reported a high prevalence of dysmenorrhea [53\%], chronic pelvic pain [39.6\%] and dyspareunia [18.3\%] with isthmocele. ${ }^{17-19}$ Pain is attributed to abnormal muscle contractions caused by altered uterine physiology as a result of the defect, and continuous efforts of the myometrium to expel the collection in the isthmocele.Histopathological findings have reported associated chronic inflammation, small polyps and lymphocytic infiltration in the region of the defect. Presumably, it a combination of altered physiological processes that is responsible for pain mechanism with these lesions. ${ }^{3} \mathrm{~A}$ significant relationship has been described to exist between dysmenorrhea, width of the defect, and abnormal bleeding.Van der Voet et al ${ }^{14}$ reported a $97 \%$ improvement in pain on resection of isthmoceles.

Isthmocele has been found to be associated with secondary infertility. It is hypothesized that isthmocele acts in a manner similar to hydrosalpinx, with local accumulation of inflammatory mediators causing a fall in $\mathrm{pH}$ of the uterine milieu. This has a toxic effect on sperms and embryo nidation. There is associated alteration 
of cervical mucus, which further contributes to adverse effect on sperm motility. A retrograde flow of collected blood especially in women with a retroverted uterus couldbe another reason for decreased fertility in some cases. This maylead to an altered endometrium, and cause it to become non responsive to embryo implantation.

\section{Diagnosis}

Diagnosis is suggested by clinical symptoms and previous history of cesarean section. It is confirmed by radiological and hysteroscopic findings. In the present scenario, there are no guidelines or standardization of diagnostic techniques. Ultrasonography is the first radiologic diagnostic modalitiy used to aid diagnosis. The role of other methods such as Saline infusion sonography, hysterosalpingography and MRI is being evaluated. More recently, hysteroscopy and laparoscopy have increasingly been used, especially due to the reason that they can serve as both a diagnostic as well as a therapeutic measure simultaneously.

\section{Ultrasonography}

Transvaginal ultrasonography [TVS] is the most common used modality for diagnosis of isthmocele whichis seen as a wedge shaped anechoic area in the isthmus or at the site of cesarean scar with a depth of at least $1 \mathrm{~mm}$ and an indentationof the myometrium of at least $2 \mathrm{~mm}$.

A "U" or "V" shaped notch is the most common finding on TVS. Nevertheless less typical images include those corresponding to attenuation of myometrium at the scar site or 'niche'. [Monteagudo et al, 2001] ${ }^{15}$ These defects might bear different shapes such as a thin linear defect, focal saccular outpouching, unilateral or bilateral diverticula and fistula, and different locations such as the body of the uterus, lower uterine segment, upper endocervical canal and the isthmus. ${ }^{16}$

Naji [2011] described a method of evaluation of isthmocele scar, which remains the most commonly used presently. ${ }^{17}$ The scar should be examined in both transverse and sagittal planes and the size, depth and thickness of residual myometrium be measured..$^{18}$ The width of myometrium above and below the defect can also be measured and the ratio of residual myometrium and myometrium overlying the defect calculated.
The best time for TVS is controversial with some investigators recommending that it be performed at mid-cycle where there is abundant cervical mucus which can act as a natural contrast medium ${ }^{19}$. Others have suggested early follicular phase to be the best phase for TVS where low height of the endometrium helps to define the defect more precisely. ${ }^{17} \mathrm{~A}$ newer modality is the use of three dimensional TVS but its use is limited in view of it technical differences from the conventional ultrasound.

\section{Hysterosalpingogram [HSG]}

Isthmocele can be seen as an incidental finding at HSG as diverticula or thin linear defects at the lower uterine cavityin approximately $60 \%$ patients undergoing this procedure. ${ }^{20}$

\section{Sonohysterography}

In this method, ultrasonography contrast media in the form of gel or saline is used for delineation of the defect. Various shapes of the scar can be identified such as triangular, semicircular, square, circular, droplet and in the presence of inclusion cysts. The shapes, however, have no bearing on symptomatology and any significance is yet to be determined. ${ }^{16}$

A study comparing TVS with sonohysterography for diagnosis of isthmocele found a higher prevalence with sonohysterography [56-84\%] as compared to TVS [24-70\%]. The authors suggested further evaluation to find out if this was an incidental finding or a reflection of higher sensitivity of sonohysterography for diagnosis of isthmocele. ${ }^{20}$

\section{Magnetic Resonance Imaging [MRI]}

It is a good modality to measureisthmocele. MRI can evaluate size of the defect, residual thickness, contents of the pouch and also gives a fair idea about the surrounding pelvic area. Its high cost and low availability limit its usage.

\section{Diagnostic Hysteroscopy}

Diagnostic hysteroscopy gives us a direct visualization of the pouch along with its contents. The defect can be seen as a cavity in the anterior wall of uterine isthmus or in the upper third of the cervical canal. Occasionally, a double arch of fibrous tissue can be seen and a dome identified between the two arches. Endometrium seen inside the defect is usually congested, appearing in different stages of inflammation with neo- 
vascularisation and tendency of contact bleeding. Often a brownish discoloration due to collected blood can be seen. This aids in diagnosis by excluding other causes of abnormal uterine bleeding like polyps and submucosal fibroids.

\section{Diagnostic laparoscopy:}

It helps to assess the outer surface of the defect and can be used in conjuction with hysteroscopy where the principle of diaphanoscopy can be used to identify the defect. Two light sources, one inside the uterine cavity delineating the defect [on hysteroscopy] and the other inside the abdomen [on laparoscopy] can be used simultaneously. The laproscopic light source can be partially dimmed for better identification of the defect, with the hysteroscopic light source at full illumination.

\section{Classification:}

Two different systems have been suggested for classification of isthmocele. Gubbini et al [Table $1]^{22}$ suggested a classification based on the surface area of the Isthmocele. They considered isthmocele akin to an isosceles triangle and used the formula (Base $\mathrm{x}$ Height)/2, to calculate the surface area.

Table 1: Classification of Isthmocele [Gubbini et al]

\begin{tabular}{|l|l|}
\hline Grade & Surface Area \\
\hline $1^{*}$ & Less than $15 \mathrm{~mm}^{2}$ \\
\hline 2 & 16 to $25 \mathrm{~mm}^{2}$ \\
\hline 3 & More than $25 \mathrm{~mm}^{2}$ \\
\hline
\end{tabular}

* More than $55 \%$ isthmoceles were classified as Grade 1 by Gubbini et al.

Ofili-Yebovi D et al classified isthmocele on the basis of myometrial thinning at the site of defect. They calculated the ratio between the myometrial thickness at the level of the defect and the thickness of the adjacent myometrium.A severe defect was defined as a ratio $>50 \%$ and dehiscence as a ratio equal o superior to $80 \% .^{22}$

According tosome other authors cesarean scar defect is said to be as severe when the thickness of remainingmyometrium is less than $2.2 \mathrm{~mm}$ visualized by transvaginal ultrasonography or $2.5 \mathrm{~mm}$ in womenundergoing sonohysterogram. ${ }^{23}$

\section{Management:}

The management should be guided by the severity and type of symptoms. Both medical and surgical methods have been described for the management of isthmocele. The definitive management remains surgical with excision and repair of the uterine defect by laparotomy, laparoscopy, hysteroscopy or by a vaginal approach.

\section{Medical Management}

Menstrual irregularities can be managed by oral contraceptive agents in women who are not desirous of pregnancy in future.However, the efficacy of drugs is still debated and there is conflicting literature on the subject. ${ }^{24,25}$

\section{Surgical Management}

\section{Operative Hysteroscopy}

Hysteroscopy is a good method to diagnose as well as treat cesarean scar defect. The distal fibrotic margin is resected to drain the already collected fluid and prevent further collection of fluid in the cavity. Some authors have also described resection of the proximal margin. It is important to realize that hysteroscopic resection can lead to a weakening of muscle in the area of the scar, which may prove hazardous if subsequent pregnancies are desired.The procedure carries an inherent risk of injury to adjacent structures especially urinary bladder.

Early detection of impending bladder perforation can be done by instillation of methylene blue dye in the bladder before the procedure. Likewise, simultaneous ultrasonography can be performed to detect bladder injury. Bipolar coagulation can also be used for this purpose. It results in retraction of the tissues and fragile inflammatory vessels in the cavity can be coagulated. Such procedures should be avoided if the residual myometrial length is less than $2 \mathrm{~mm}$ to avoid uterine perforation and bladder injuries. ${ }^{26}$

\section{Laparoscopic Management of Isthmocele}

The first laparoscopic isthmocele repair was carried out Jacobson et alin 2003. ${ }^{27}$ Women with a residual myometrial length less than $3 \mathrm{~mm}$, and desirous of future pregnancy are ideal candidates for laparoscopic management. Its great advantage over hysteroscopic resection remains that this is reparative surgery, where we restore the myometrial thickness. The procedure involves identification of the defective uterine area, bladder dissection, resection of Isthmocelefollowed byresuturing the area laproscopically.

A major difficulty in performing the procedure 
laproscopically is that the defect may not be very evident when seen laparoscopically and hysteroscopic guidance may be required many times to localize the defect. Therefore, first, the defect is recognized hysteroscopically, marked with the help of hegar dilator or by diaphanoscopy and then the surgery is proceeded laproscopically. Some authors describe resection of the entire uterine wallwhile the others leave the mucosa intact and excise only the muscular layer. ${ }^{28,29} \mathrm{Klemm} \mathrm{P}$ et al.described a combined laparoscopic-vaginal approach to repair the defect. ${ }^{30}$ Later on,Donnez O et al described a complete laparoscopic approach for the same. ${ }^{31}$ It is recommended to wait at least for one year before planning a subsequent pregnancy. Significant reduction in symptoms has been reported in the literature after the correction.

\section{Laparatomic Reconstruction}

The principles followed are similar to laproscopic reconstruction but the disadvantage is that patient has to undergo repeated laparotomies and the associated complications.

\section{Vaginal Reconstruction}

This is another minimally invasive method to repair the scar defect. The Isthmocele is approached vaginally, pseudosac excised and the uterine wall repaired in two layers. The risk of injury to urinary bladder or difficulty to gain vaginal access in cases with high uterine incision remain possible disadvantages of the procedure.

\section{Hysterectomy}

For some women, it may be the treatment of choice especially if future fertility is not desired and other associated conditions are present for which hysterectomy might be indicated.

\section{Conclusion:}

- Isthmocele is a novel entity that is largely iatrogenic and has gained global relevance in the past decade. It may be associated with significant morbidity such as postmenstrual bleeding, pelvic inflammatory disease, infertility and cesarean scar pregnancy.

- It is extremely important to increase the awareness of isthmocele due to wide obstetric and gynaecological implications of the condition.

- Transvaginal ultrasound is majorly diagnostic but other modalities such as sonohysterography, magnetic resonance imaging and diagnostic hystero-laparoscopy may be required occasionally to complement the observations.

- The mainstay of treatment remains surgery, however oral contraceptive pills can be used in specific clinical situations.

\section{Conflict of Interest: None}

Funding: None 
International Journal of Human and Health Sciences Vol. 03 No. 03 July'19

\section{Bibliography:}

1. Gubbini G, Casadio P, Marra E. Resectoscopic correction of the "isthmocele" in women with postmenstrual abnormal uterine bleeding and secondary infertility. J Minim Invasive Gynecol. 2008;15(2):172-5.

2. Morris H. Surgical pathology of the lower uterine segment caesarean section scar: is the scar a source of clinical symptoms? Int J GynecolPathol. 1995;14(1):16-20.

3. Osser OV, Jokubkiene L, Valentin L. High prevalence of defects in Cesarean section scars at transvaginal ultrasound examination. Ultrasound Obstet Gynecol. 2009;34(1):90-7.

4. Bij de Vaate AJ, van der Voet LF, Naji O, Witmer M, Veersema S, Brolmann HA, Bourne T, Huirne JA. Prevalence, potential risk factors for development and symptoms related to the presence of uterine niches following Cesarean section: systematic review. Ultrasound Obstet Gynecol. 2014;43(4):372-82.

5. Armstrong V, Hansen WF, Van Voorhis BJ, Syrop $\mathrm{CH}$. Detection of cesarean scars by transvaginal ultrasound. Obstet Gynecol. 2003;101(1):61- 5.

6. Ofili-Yebovi D, Ben-Nagi J, Sawyer E, Yazbek J, Lee C, Gonzalez J, Jurkovic D. Deficient lower-segment Cesarean section scars: prevalence and risk factors. Ultrasound Obstet Gynecol. 2008;31(1):72-7.

7. Rozenberg P, Goffinet F, Phillippe HJ, Nisand I. Ultrasonographic measurement of lower uterine segment to assess risk of defects of scarred uterus. Lancet. 1996;347(8997):281-4.

8. Roberge S, Demers S, Berghella V, Chaillet N, Moore L, Bujold E. Impact of single- vs double-layer closure on adverse outcomes and uterine scar defect: a systematic review and metaanalysis. Am J Obstet Gynecol. 2014; 211(5): 453-60.

9. Vervoort, AJ, Uittenbogaard LB., Hehenkamp, WJ, Brolmann HA, Mol BW, Huirne JA. Why do niches develop in Caesarean uterine scars? Hypotheses on the aetiology of niche development. Hum Reprod. 2015, 30(12):2695-702.

10. Fabres C, Aviles G, De La Jara C, Escalona J, Munoz JF, Mackenna A, Fernandez C, Zegers-Hochschild F, Fernandez E. The cesarean delivery scar pouch: clinical implications and diagnostic correlation between transvaginal sonography and hysteroscopy. J Ultrasound Med. 2003; 22(7): 695-700

11. Pomorski M, Fuchs T, Rosner-Tenerowicz A. and Zimmer M. Standardized ultrasonographic approach for the assessment of risk factors of incomplete healing of the cesarean section scar in the uterus. Eur
J ObstetGynecolReprod Biol. 2016; 205: 141-5.

12. van der Voet LF, Vervoort AJ, Veersema, S, BijdeVaate AJ, Brolmann HA, Huirne JA. Minimally invasive therapy for gynaecological symptoms related to a niche in the caesarean scar: a systematic review. BJOG. 2014;121(2):145-56.

13. van der Voet LF, Bij de Vaate AM, Veersema S. Long-term complications of caesarean section. The niche in the scar: a prospective cohort study on niche prevalence and its relation to abnormal uterine bleeding. BJOG. 2014;121(2):236-44.

14. Vervoort AJMW, Van der Voet LF, Witmer M, Thurkow AL, Radder CM, van Kesteren PJM, et al. The HysNiche trial: hysteroscopic resection of uterine caesarean scar defect (niche) in patients with abnormal bleeding, a randomised controlled trial. BMC Womens Health. 2015;15:103-111.

15. Wang CB, Chiu WW, Lee CY, Sun YL, Lin YH, Tseng CJ. Cesarean scar defect: correlation between Cesarean section number, defect size, clinical symptoms and uterine position. Ultrasound ObstetGynecol, 2009, 34 (1): 85-9.

16. Monteagudo A, Carreno C, Timor-Tritsch IE. Saline infusion sonohysterography in nonpregnant women with previous cesarean delivery: The "Niche" in the scar. J Ultrasound Med. 2001;20: 1105-1115.

17. Ahmadi F, Torbati L, Akhbari F, Shahrzad G. Appearance of uterine scar due to previous cesarean section on hysterosalpingography: various shapes, locations and sizes. Iran J Radiol. 2013; 10(2):10310

18. Naji O, Abdallah Y, Bij De Vaate AJ, Smith A, Pexsters A, Stalder C, et al. Standardized approach for imaging and measuring cesarean section scars using ultrasonography. Ultrasound Obstet Gynecol. 2012;39(3) 252-59.

19. Tulandi T, Cohen A. Emerging manifestations of cesarean scar defect in reproductive-aged women. $J$ Minim Invasive Gynecol. 2016;23(6):893-902.

20. Fonda J. Ultrasound diagnosis of caesarean scar defects. AJUM. 2011;14(3):22-30.

21. Surapaneni K, Silberzweig JE. Cesarean section scar diverticulum: appearance on hysterosalpingography. AJR Am J Roentgenol. 2008;190(4):870-74.

22. Gubbini G, Centini G, Nascetti D, Marra E, Moncini I, Bruni L, et al. Surgical hysteroscopic treatment of cesarean-induced isthmocele in restoring fertility: prospective study. J Minim Invasive Gynecol. 2011; 18(2): 234-7.

23. VikharevaOsser O, Valentin L. Risk factors for incomplete healing of the uterine incision after 
International Journal of Human and Health Sciences Vol. 03 No. 03 July'19

caesarean section. BJOG. 2010; 117(9): 1119-26.

24. Bij de Vaate AJ, Brolmann HA, van der Voet LF, van der Slikke JW, Veersema S, Huirne JA. Ultrasound evaluation of the Cesarean scar: relation between a niche and postmenstrual spotting. Ultrasound Obstet Gynecol. 2011; 37(1): 93-9.

25. Tahara M, Shimizu T, Shimoura H. Preliminary report of treatment with oral contraceptive pills for intermenstrual vaginal bleeding secondary to a cesarean section scar. FertilSteril. 2006; 86(2): 477-9

26. Di SpiezioSardo A, Florio P, Nazzaro G, Spinelli M, Paladini D, Di Carlo C, Nappi C. Hysteroscopic outpatient metroplasty to expand dysmorphic uteri (HOME-DU technique): a pilot study. Reprod Biomed. 2015;30(2):166-74

27. Setubal, A., Alves, J., Osório, F., Guerra A, Fernandes R, Albornoz J, Sidiroupoulou Z. Treatment for uterine isthmocele, and a pouchlike defect at the site of a cesarean section scar. J Minim Invasive Gynecol. 2018; 25(1):38-46.

28. Chen Y, Chang Y, Yao S. Transvaginal Management of Cesarean Scar Section Diverticulum: A Novel Surgical treatment. Med Sci Monit. 2014;20:1395-99

29. Dosedla E, Calda P. Outcomes of laparoscopic treatment in women with cesarean scar syndrome. Med Sci Monit. 2017; 23: 4061-66.

30. Klemm P, Koehler C, Mangler M, Schneider U, Schneider A. Laparoscopic and vaginal repair of uterine scar dehiscence following cesarean section as detected by ultrasound. J Perinat Med. 2005; 33(4): 324-31.

31. Donnez O, Jadoul P, Squifflet J, Donnez J. Laparoscopic repair of wide and deep uterine scar dehiscence after cesarean section. FertilSteril. 2008; 89(4):974-80. 